\title{
La contaminación visual en Bogotá: análisis de cargas visuales en localidades con alta estimulación publicitaria
}

\author{
Visual pollution in Bogota: analysis of visual load in \\ locations with high advertising stimulation
}

\section{Carlos Andrés Arango ${ }^{1}$ Guillermo Rodríguez-Martínez ${ }^{2}$ Fernando Marroquín-Ciendúa ${ }^{3}$}

Recibido: junio 30 de 2020

Aceptado: diciembre 02 de 2020

\begin{abstract}
Resumen
La contaminación visual se define como un efecto perceptual, compuesto de desorden y exceso de imágenes dentro del campo visual. El presente estudio tuvo por propósito establecer niveles de carga visual, manifestados en 13 paisajes urbanos de la ciudad de Bogotá (Colombia). Se quisieron establecer niveles de asociación entre las diferentes variables que aportan en los índices de carga visual (ICVi), al igual que la diferencia que existe entre la contaminación visual detectada en dos planos distintos del campo visual (uno inferior y otro superior) en relación al horóptero visual vertical de los observadores. 130 personas participaron en el estudio. Para definir los niveles de carga visual, se implementó la metodología del trazado de retículas sobre fotografías, por las que se emula la disposición de los estímulos visuales en la imagen retiniana. Se concluye que la carga visual es mayor cuando los objetos están al nivel o por debajo de los $15^{\circ}$ en el campo visual. Los estímulos visuales que están por encima de los $15^{\circ}$, si bien aportan carga visual, suponen un índice de contaminación visual significativamente menor.
\end{abstract}

Palabras clave: contaminación visual, carga visual, entorno urbano, urbanismo.

\begin{abstract}
The visual contamination is defined as a perceptual effect composed of disorder and excess of images within the visual field. This study was aimed at establishing visual load levels manifested in 13 urban landscapes of Bogotá City (Colombia). We wanted to establish levels of association between the different variables that contribute to visual load indexes (ViLI), as well as the difference that exists between the visual contamination detected in two different planes of the visual field (one lower and one higher) in relation to the observers'vertical visual horopter. 130 people participated in the study. To define the levels of visual load, the reticulum tracing methodology was implemented on photographs that emulate the arrangement of visual stimuli into the retinal image. It is concluded that the visual load is greater when the objects are at the level or below $15^{\circ}$ in the visual field. Although visual stimuli that are above $15^{\circ}$ provide visual load, they imply a significantly lower index of visual contamination.
\end{abstract}

Keywords: visual pollution, visual load, urban environment, urbanism.

1 Profesional en Publicidad, Magíster en Publicidad, Universidad Jorge Tadeo Lozano, Bogotá, Colombia. E-mail: carlosa.arangol@ utadeo.edu.co

ORCID: https://orcid.org/0000-0002-2786-3653

2 Profesional en Publicidad, Doctor en Psicología, Universidad Jorge Tadeo Lozano, Bogotá, Colombia. E-mail: guillermo.rodriguez@ utadeo.edu.co

ORCID: https://orcid.org/0000-0003-4329-5745

3 Publicista, Doctor en Psicología, Universidad Jorge Tadeo Lozano, Bogotá, Colombia. E-mail: fernando.marroquinc@utadeo.edu.co ORCID: https://orcid.org/0000-0002-2213-4566 


\section{Introducción}

El concepto de carga perceptiva, corresponde a la cantidad de información involucrada en el procesamiento perceptual del ser humano, y se define operativamente en términos de la cantidad de estímulos o de requisitos perceptivos implicados en una observación particular (Macdonald, \& Lavie, 2011). Cuando se hace referencia a carga perceptiva visual, se alude a la cantidad de procesamiento visual implicado por la cantidad de estimulación visual proferida, donde la carga se configura tanto por la cantidad de estímulos como por su disposición dentro del campo visual, configuración que repercute en la determinación de la complejidad de una escena visual (Milam, El-Nasr, Moura \& Bartram, 2011). Cuando esta complejidad es estimada como de alto nivel, se asume que las condiciones estimulares son de alta carga perceptiva, lo que conduce a un procesamiento reducido de estímulos desatendidos (Lavie, Beck \& Konstantinou, 2014). Un observador, cuando debe atender una carga perceptual visual alta, requiere de mayor procesamiento neuronal, esto porque existe un efecto demostrado de esta sobre un incremento de las respuestas de la corteza visual (Molloy, Griffiths, Chait \& Lavie, 2015).

La carga visual perceptiva, da sustento a la noción de contaminación visual, la cual se define como: un efecto perceptual compuesto de desorden y exceso de objetos e imágenes en el campo visual (Alemán, 2013), tales como: anuncios publicitarios, mobiliario urbano, luces y características de iluminación (Cinzano \& Falchi, 2014), junto a otros objetos que hacen compleja la decodificación del paisaje (Chmielewski et al., 2016; López, 2012). El contraste visual que se propicia en el campo visual, y en donde los objetos artificiales pueden en ocasiones contribuir a percibir contaminación visual en áreas rurales (Flad, 1997), se suma en el abordaje de la problemática, indicando qué estimulación visual natural propia de un escenario puede verse afectada por lo que el hombre añada dentro de él (Chmielewski et al., 2018).
Ha existido un interés por situar a la contaminación visual como un objeto de estudio (e.g. Chmielewski et al., 2016), esto porque desde diferentes campos se reconoce la necesidad de indagar sobre el particular, como es el caso del mercadeo y la publicidad (e.g. Ha \& Litman, 1997; Olivares, 2009; Granda, 2017), o como también sucede en el ámbito del urbanismo y el paisajismo (e.g. Iveson, 2012; Aydin y Nisanci, 2008). El estudio acá descrito, tuvo por objetivo establecer los niveles de carga visual que se derivan de la observación de escenarios urbanos de la ciudad de Bogotá, que fueran tipificados como entornos que cumplen los requisitos para ubicar publicidad exterior, incluyendo vallas a gran altura, y que efectivamente tuvieran material publicitario y otros objetos potencialmente propiciadores de carga visual. Se tipificaron los elementos de carga visual en 15 categorías, a saber: avisos, pendones, afiches, andenes rotos, huecos, antenas, tanques, puestos ambulantes, vallas publicitarias, culatas, rayones, basura, cables, postes y cerramientos, para estimar el nivel de asociación entre ellos y los niveles del índice de carga visual (ICVi), considerando 13 áreas urbanas observadas en la ciudad de Bogotá.

El estudio también tuvo por propósito determinar qué elementos visuales estimados como generadores de carga visual, están asociados al Índice de Carga Visual (ICVi), tomando en consideración dos campos visuales distintos, uno de primer nivel (comprendido por el área del campo visual que va desde la línea paralela a la horizontal que sale del ojo, hasta los $15^{\circ}$ hacia arriba), y otro de segundo nivel (área por encima de los $15^{\circ}$ ). Así mismo, se quiso determinar si existían asociaciones significativas entre los registros medios y altos de carga visual y los diferentes ítems dentro del paisaje urbano, considerando los dos campos visuales tomados en referencia al horóptero visual. También se quiso, de forma descriptiva, identificar las áreas urbanas con mayores y menores índices de carga visual. La existencia o no de una diferencia significativa entre los reportes referidos a cargas visuales medias y los reportes de cargas visuales altas, fue algo que se definió como otro objetivo del 
estudio, lo mismo que establecer si se hacía más manifiesta la percepción de carga visual en el campo visual de primer nivel con respecto a la carga visual reportada para el campo visual de segundo nivel, tomando en consideración que las vallas de gran formato se emplazan en este último.

\section{Marco teórico y metodología}

\subsection{Retículas para medición de carga visual}

Para efectos de evaluar la carga visual dentro de un paisaje urbano, se pueden utilizar instrumentos que implican la mezcla de indicadores por parametrización de retículas y de estimaciones subjetivas dadas por observadores (sujetos de investigación), quienes son expuestos a fotogramas que emulan el plano de la imagen retiniana para luego hacer valoraciones sobre la dificultad relativa a procesar la estimulación visual urbana (Chmielewski et al., 2016).

Cuando se estima elaborar retículas para esta evaluación, emergen criterios esenciales a considerar, como son el objetivo y altura de la imagen, el ángulo de visión y encuadre, las dimensiones del primer plano y del segundo plano, más el primer y segundo niveles de la retícula. Tras considerar cada uno de estos factores, se configura una retícula de análisis de carga visual en el paisaje, partiendo de imágenes fotográficas digitales que, con una resolución de imagen, resultan adecuadas para tener el registro arquitectónico y paisajístico apropiado para evaluar niveles de armonía entre elementos publicitarios y objetos en general, con respecto al paisaje urbano (Aydin \& Nisanci, 2008).

La imagen a ser evaluada, puede estar determinada por el encuadre de $1920 \times 1080$ pixeles (formato HD para cine y TV), donde el centro del cuadro corresponde a la visión perpendicular del observador y paralela a la línea de piso (relación entre los ejes marcados por los horópteros vertical y horizontal dentro del área de Panum) a una altura aproximada de 1.70 metros (que puede variar entre cada muestra poblacional dependiendo del promedio de estatura en seres humanos).

El área de fusión de Panum (ver figura 1), es el conjunto de puntos en el espacio visual que tienen su correspondiente imagen proyectada en puntos en las dos retinas (Lakshminarayanan, Rajaram, \& Joseph, 2002). La longitud de la línea vertical del campo visual (horóptero vertical), es usualmente percibida en una dimensión lineal (longitud) diferente que la horizontal (horóptero horizontal), configurándose una aparente asimetría. Esta interpretación asimétrica del campo visual, si bien no está asociada a claves de información de orden gravitacional, si está definida por mecanismos internos de representación perceptual (Lipshits et al., 2001). Estas disposiciones de orden funcional, han repercutido en la manera en que se diseñan plantillas, retículas e, incluso, pantallas de los dispositivos para rastreo de actividad oculomotora (Holmqvist et al., 2011), asumiendo que la agudeza estereoscópica se encuentra en el rango de los dos a los seis segundos de ángulo.

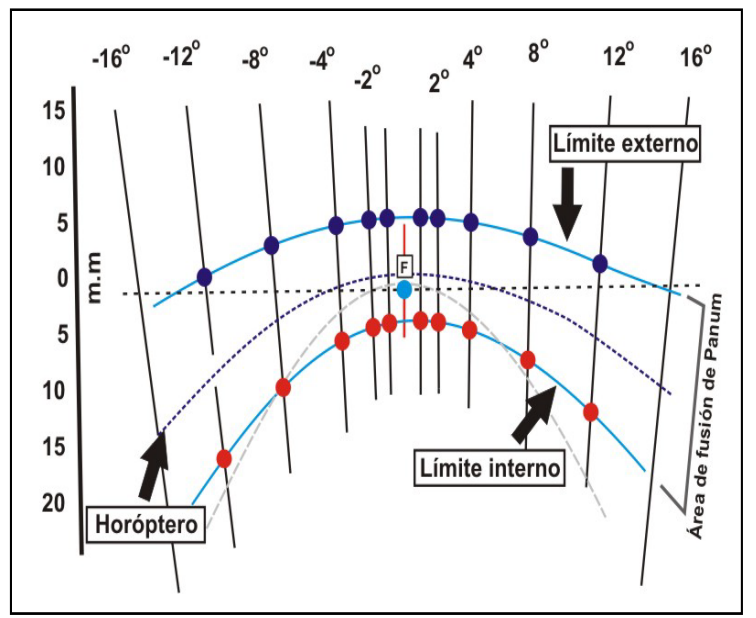

Figura 1. El área de fusión de Panum y el punto de enfoque central (F) (Adaptada de "The perception of depth", 2011).

Para efectos de definir una retícula de análisis, se estima que el ángulo de visión del paisaje es de 60 grados (hacia arriba) desde el ojo del 
observador, para de esta manera homologar el formato fotográfico HD. Así, de manera horizontal se tiene una apertura del paisaje a 90 grados, donde el ángulo de visión vertical se define desde el observador y tomando como referencia el punto de cruce de su línea visual de observación con la vertical trazada desde piso, a 2.8 metros de distancia desde la posición del observador (ver figura 2). Se dispone una retícula de 20×20 unidades, para medir el área que abarcan los elementos presentes en el campo observable y estimar la carga visual por cada elemento observado. Cada unidad es, en sí misma, el cuadrado base por el cual se configura la retícula, que a su vez se constituye en la base para análisis de carga visual en planos bidimensionales que emulan la imagen retiniana.
La retícula se divide en dos niveles, denominados primer y segundo nivel. Como se había referido previamente, el primer nivel es el área del campo visual que va desde la línea trazada desde el ojo y que es paralela a la horizontal, hasta los $15^{\circ}$ hacia arriba, como se aprecia en la figura 2. El segundo nivel (ver figura 2), alude al campo que está por arriba de los $15^{\circ}$ (más de quince grados verticales de la visual), siguiendo el vector del horóptero vertical en dirección al zenit físico. En lo sucesivo, se aludirá a estos niveles como campo visual de primer nivel y campo visual de segundo nivel, respectivamente.

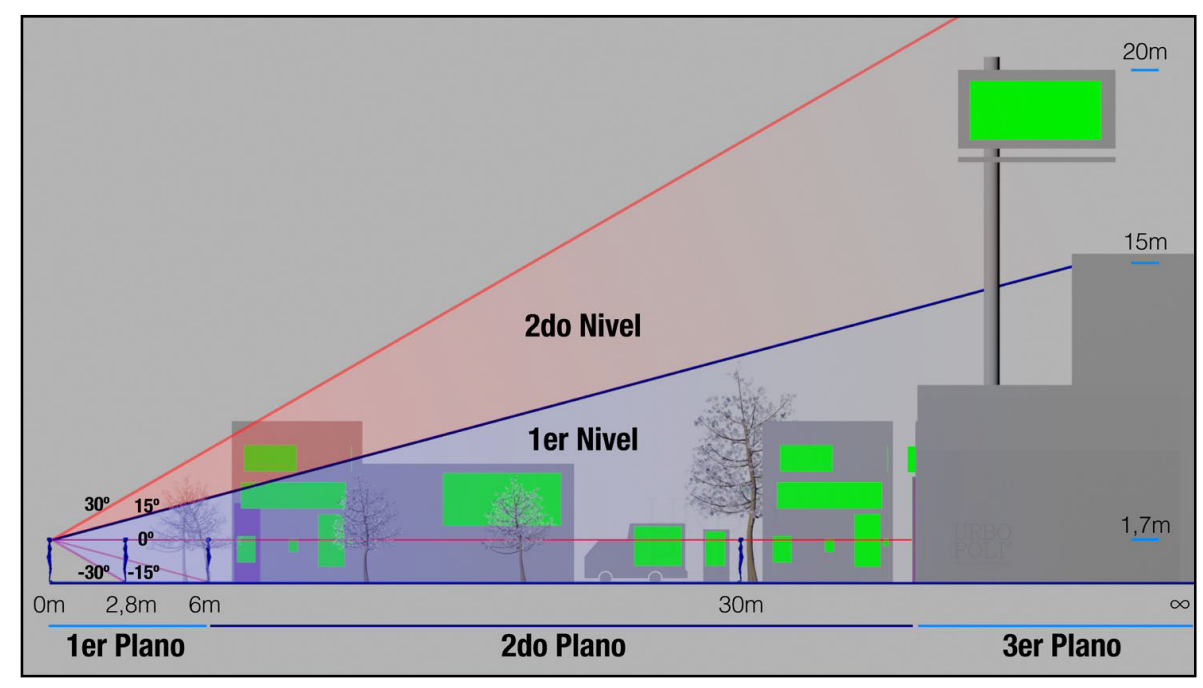

Figura 2. Los campos visuales de primer y segundo nivel.

Se debe considerar que el ojo humano, está mayormente habituado a buscar los objetos y estímulos físicos que están dentro de su área de Panum, en relación a la dirección paralela a la horizontal o trazando vectores por los que sus fijaciones oculares se manifiestan desde el suelo hasta los $15^{\circ}$. Esto en relación a individuos que normalmente se desplazan de manera tal que el eje de su tronco y cabeza (ejes idiotrópicos), están en paralelo a la vertical y perpendicular a la horizontal; hecho que implica una relación entre la posición del cuerpo y la afectación de lo percibido visualmente dentro del campo visual (Lopez, Bachofner, Mercier, \& Blanke, 2009). En la figura 3, se aprecian los dos niveles de retícula en una perspectiva en la que se evidencia la cuadrícula en relación al que sería el tamaño en pixeles de la misma. Las vallas de gran formato, como también se aprecia en las figuras 2 y 3 , están inscritas en los rangos angulares por los que se define el campo visual de segundo nivel. 


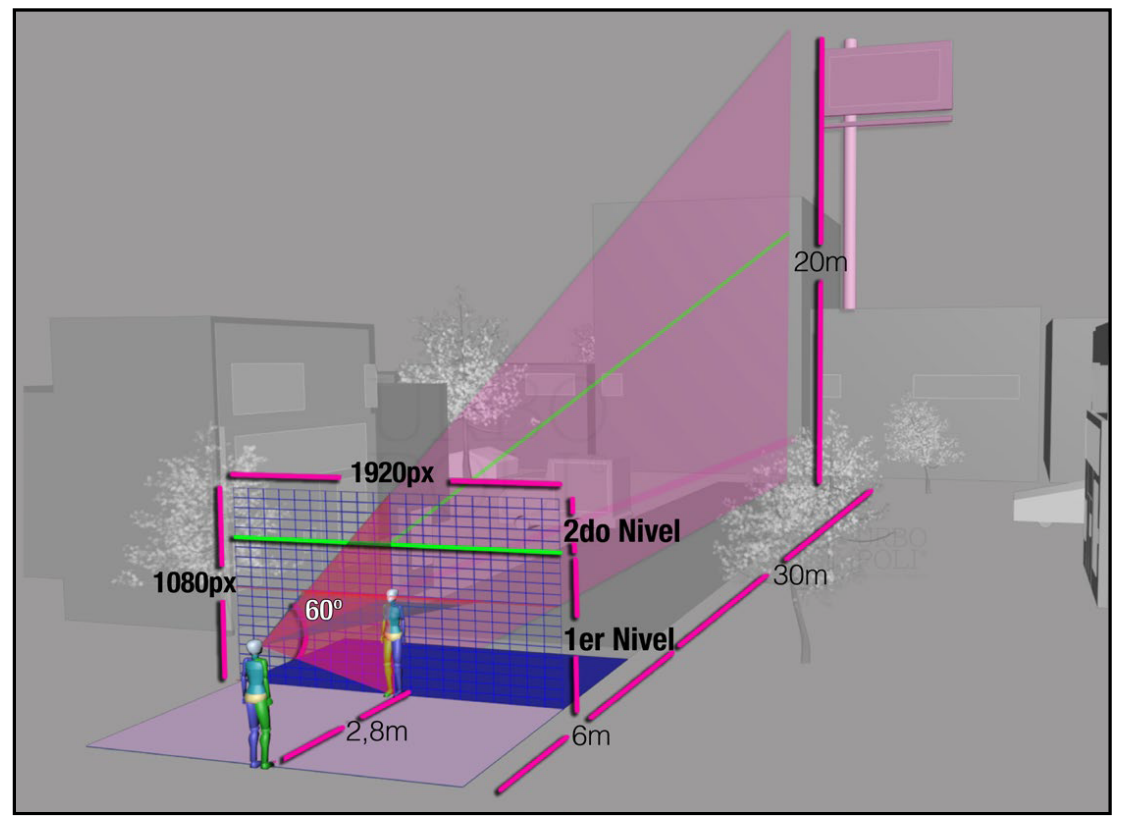

Figura 3. Los campos visuales de primer y segundo nivel en referencia a la retícula.

\section{2 Índice de carga visual}

Un Índice de Carga Visual (ICVi), tiene como finalidad medir la carga visual en un paisaje determinado, a través de la relación mostrada por las variables espacio y estimulación visual generadora de carga visual (Chmielewski et al., 2016). El índice es de tipo cuantitativo, pues se trata de una representación numérica por la cual se obtienen indicadores que dan cuenta del peso o carga visual, contenido en una escena o paisaje visual.
El ICVi está definido por ecuaciones, donde: A y $B$ son los componentes objetivos espaciales; $A$ es el área ocupada por un elemento generador de carga visual incluido en el índice y que se halla ubicado en el campo visual de primer nivel, y B, el área ocupada por un elemento generador de carga visual incluido en el índice y que se halla ubicado en el campo visual de segundo nivel; la ponderación de los niveles 1 y 2 de la retícula, corresponden, respectivamente, a los niveles de ponderación 0.003 y 0.001 (ver ecuaciones 1 a 3). Esos niveles de ponderación, se corresponden con el peso o relevancia dado a cada uno de los dos niveles de la retícula.

$$
\begin{aligned}
& I C V i=\left[\left(0,75\left(A_{-} 1+\cdots+A_{-} n\right)+0,25\left(B_{-} 1+\cdots+B_{-} n\right)\right) / 250\right] 100 \\
& I C V i=\left[0,003\left(A_{1}+\cdots+A_{n}\right)+0,001\left(B_{1}+\cdots+B_{n}\right)\right] 100 \\
& I C V i=\left(0,003 \sum_{i=1}^{n} A_{i}+0,001 \sum_{i=1}^{n} B_{i}\right) 100
\end{aligned}
$$

El método de medición, se basa en la suma de los productos entre la ponderación del primer nivel y el área total ocupada por los elementos generadores de carga hallados en este, y la ponderación del segundo nivel y el área total ocupada por los elementos generadores de carga ubicados allí, multiplicado por cien.
El indicador se interpreta asumiendo que un valor de $100 \%$, significa que el paisaje valorado se encuentra totalmente cargado, es decir, que genera la mayor carga visual posible; en tanto que un valor de $0 \%$, indica que el paisaje en cuestión carece de cualquiera de los elementos generadores de carga visual que componen el 
índice. Resultados menores a $100 \%$ y superiores a $0 \%$, se refieren a la proporción del paisaje valorado que se encuentra cargado visualmente por los elementos del índice. Este indicador se construyó a partir de la información recabada en la Guía para Diseño, Construcción e Interpretación de Indicadores, concebida por el Departamento Administrativo Nacional de Estadística, en Colombia (DANE). El modelo de medición basado en uso de retículas más la medición mediante el ICVi, fueron implementados en el presente estudio.

\subsection{Parametrización de los paisajes urbanos}

Se capturaron una serie de fotografías de entornos urbanos para la medición de cargas visuales, sobre la base de que cada imagen fuese una emulación del campo visual del observador en el contexto de su interacción con el paisaje urbano (Frank et al., 2013). Todas las fotografías fueron tomadas por profesionales, con un lente gran angular de 24 a 35 m.m., homogenizando la composición visual según parámetros ópticos definidos por la retícula de medición, constituida por un total de 400 sub-áreas rectangulares (ver figura 4). Cada fotografía fue debidamente reticulada dentro de una hoja de cálculo, buscando identificar los elementos que potencialmente podían generar carga visual. Para ese propósito, se asignó el código 1 (uno) para referir la existencia de elementos sobre el paisaje urbano, y el número 2 (dos) para los cuadros que no contuvieran elementos de carga visual. Los elementos podían ser identificados en cada fotografía mediante convenciones (letras), imputadas a cada uno de los elementos con potencial carga visual.

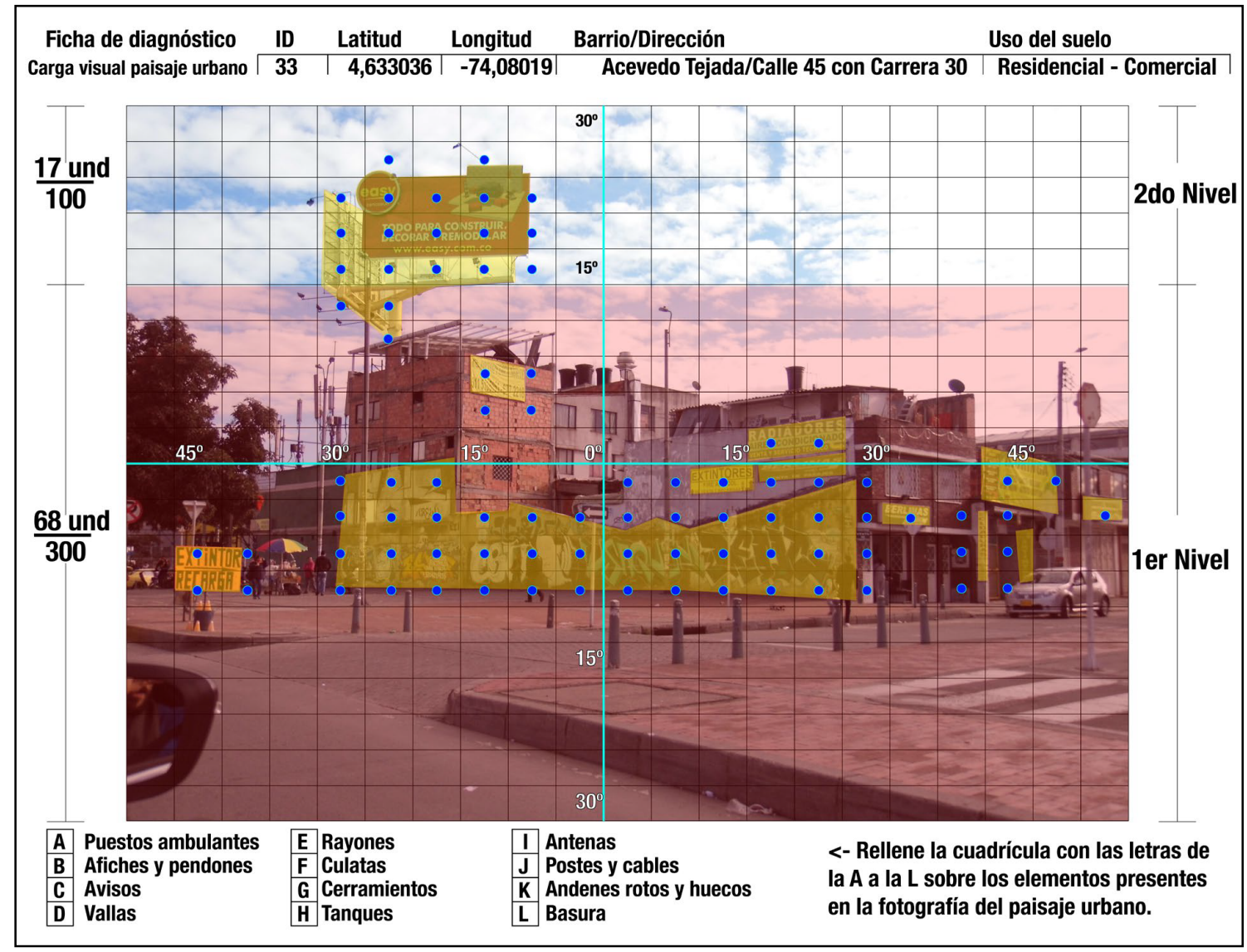

Figura 4. Parametrización de los paisajes urbanos. 
En la figura 4, se referencian los cuadrantes de la retícula que se identifican como portadores de elementos publicitarios y de contaminación visual. Se aprecia la diferenciación entre el primer y el segundo nivel, la contabilización de las unidades identificadas con carga visual y el índice de carga visual (CV). En la parte superior de la figura 4, se aprecia la ficha técnica de la imagen analizada. Por cada una de las imágenes tomadas (una por cada una de las 13 áreas seleccionadas del área metropolitana de Bogotá), cada participante del estudio diligenció la plantilla acá referida. Por cada fotografía, se resaltaron los elementos que se sobreponían o alteraban el paisaje urbano, discriminando elementos publicitarios y no publicitarios para determinar la carga visual total, siguiendo la lógica de las metodologías de evaluación de contaminación visual, en las que se discriminan los elementos visuales según su carga (Kamičaitytė-Virbašienè, Godienė \& Kavoliūnas, 2015). Así mismo, se tipificaron las áreas urbanas seleccionadas, como se describirá más adelante.

\subsection{Selección de las zonas para la captura y recolección de datos}

Se seleccionaron 13 áreas del área metropolitana de Bogotá, Colombia. Fue necesario hacer previamente una lectura de la zonificación dada por la administración distrital, en relación con la determinación de las áreas urbanas en las que se concentra la actividad publicitaria a nivel de elementos publicitarios. Un criterio de selección que se consideró para determinar las zonas de estudio, fue la lógica de emplazamiento de vallas publicitarias, que se define por el tipo de perfil vial y por la disponibilidad de suelo libre o alturas de edificaciones que no superen los 5 pisos, teniendo en cuenta que la máxima altura de las vallas es 25 metros, por normatividad propia de la ciudad de Bogotá. Luego de aplicar estos criterios de selección, se obtuvieron zonas en las que se encontraban predios con altura menor a los 5 pisos (68.294 predios contabilizados), de los cuales estaban disponibles para uso publicitario 24.860 , esto es, el $36 \%$ de los predios de la totalidad de zonas seleccionadas.

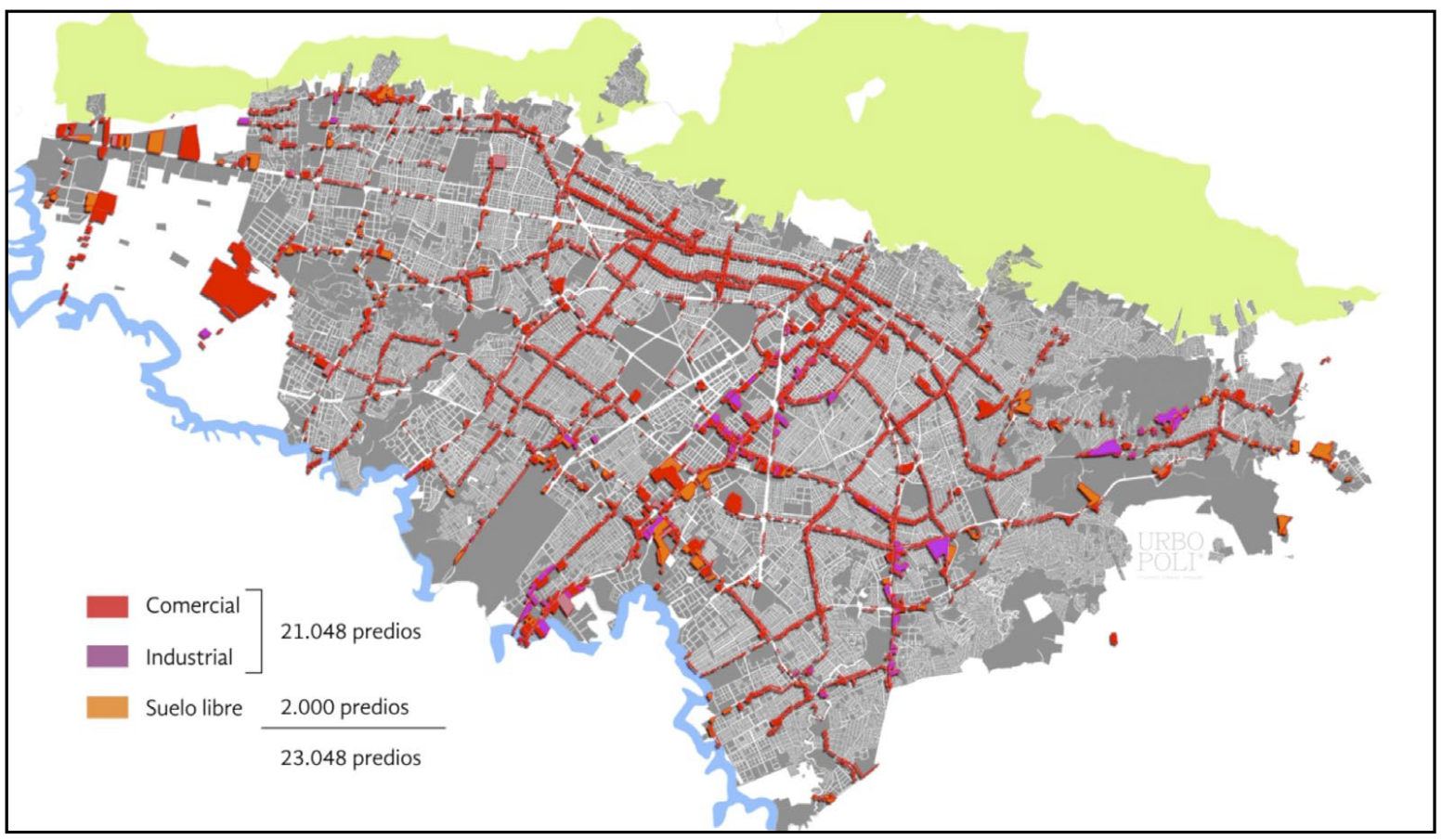

Figura 5. Mapa de Bogotá, donde se visualizan las áreas comerciales e industriales asumidas para determinar las zonas para la captura de fotografías objeto de análisis. 
Sobre la base anterior, y tras hacer una última eliminación de predios en consideración a la tipología del uso comercial e industrial, pero que cumplieran con los criterios de selección anteriormente descritos, se llegó a una base final de 21.048 predios (ver mapa en la figura 5). Posteriormente, se procedió a hacer la geolocalización de los mismos, para depurar áreas en las que se encontraban dichos predios. Se definieron así las 13 áreas que a continuación se señalan, con su correspondiente codificación (entre paréntesis), para el manejo y procesamiento de datos: (a1). Carrera 7 con calle 155C; (a2). Av. Boyacá con calle 51 ; (a3). Av. Suba con calle 120; (a4). Av. NQS con calle 70; (a5). Av. Caracas con calle 72; (a6). Carrera 7 con calle 120; (a7). Calle 20 sur con Caracas; (a8). Calle 170 - 19B; (a9); Carrera 86 - 72a; (a10); Av. Calle 13 - 69B; (a11); Av. Suba con Carrera 94C; (a12); Calle 100 con carrera 15; y, (a13). Av. Carrera 68 con calle 30 sur.

\subsection{Muestra de participantes}

Se tomó una muestra de 130 ciudadanos residentes en la ciudad de Bogotá ( $59,23 \%$ hombres, $40,77 \%$ mujeres) para hacer las valoraciones de los paisajes urbanos (todos ellos con componentes visuales de publicidad exterior). 59,23\% de los participantes en el estudio tenían una edad que oscilaba entre 18 y 30 años, seguidos por el grupo que estaba entre los 31 a los 43 años de edad (17,69\%). Hubo personas con edades comprendidas entre los 44 y 56 años (16,15\%), y un $6,92 \%$ correspondió a participantes con una edad superior a los 56 años (6,92\%). El muestreo fue no probabilístico, con criterio de inclusión referido a ser mayor de 18 años de edad y hacer parte de la población civil no institucional, que se moviliza libremente por los escenarios sometidos a estudio. A cada uno de los participantes, se les hicieron preguntas específicas sobre los elementos generadores de carga visual.

Ellos debían marcar las unidades (rectángulos) de las retículas en donde estimaran existía carga visual (ver ejemplo de retícula y del cuestionario realizado a cada participante por cada una de las 13 retículas, en la figura 4). Se otorgó un cuestio- nario (encuesta) y una retícula de análisis a cada participante por cada una de las 13 áreas urbanas, de las que se extrajo la fotografía objeto de estudio, con los criterios referentes a los niveles y planos de retícula, método instrumental utilizado en estudios sobre carga visual y evaluación de entornos y paisajes (Bechtel, Marans \& Michelson,1987; Kamičaitytè-Virbašienè et al., 2015). Se obtuvieron un total de 1820 mediciones, es decir, que ese fue el número de registros marcados en áreas dentro de las retículas observadas y que implicaron carga visual para los participantes. El período de recolección de la información más todo el procesamiento y análisis de datos, tomó dos años y diez meses, desde finales del año 2016.

\subsection{Procedimiento}

Cada participante fue debidamente instruido para que observara cada imagen reticulada, manteniendo su cabeza estática frente al portaimágenes que se adaptó para que cada fotografía quedase a una distancia de 60 centímetros, en paralelo al vector trazado por el eje idiotrópico de cada participante. Igualmente, se definió un tamaño de imagen de $46 \times 27$ centímetros, similar al área de las pantallas usadas en investigación científica para el registro de los movimientos oculares mediante dispositivos fijos (Rosa, Esteves \& Arriaga, 2014). Se establecieron intervalos para definir niveles de la variable carga visual por cada área urbana objeto de análisis, de manera que quedaran definidas cinco categorías (ver tabla 1).

Tabla 1. Categorías de los niveles de carga visual.

\begin{tabular}{lc}
\hline Nivel de carga & Valor de ICVi \\
\hline Nulo & 0 \\
Bajo & $1-10$ \\
Medio & $11-30$ \\
Alto & $31-50$ \\
Muy alto & 51 en adelante
\end{tabular}


Los niveles de asociación entre los ítems propiciadores de carga visual y los niveles del índice de carga visual (ICVi), considerando las 13 áreas urbanas observadas, fueron cotejados usando el estadístico chi-cuadrado. La diferencia entre los niveles de carga visual observados en el campo visual de primer nivel $(1 \mathrm{~N})$ y los valores registrados en el campo visual de segundo nivel $(2 \mathrm{~N})$ fue analizada mediante la prueba $U$ de Mann-Whitney. Las diferencias entre los ICVi, se analizaron con la prueba estadística ANOVA de un factor.

\section{Resultados y discusión}

Los valores promedio de ICVi más altos, se dieron en los escenarios 8 y 13 (37.7 y 33.7, respectivamente), en el campo visual de primer nivel. Los resultados fluctuaron entre $13 \%$ y $37,7 \%$ en términos de ICVi en los escenarios evaluados, respecto a un $100 \%$ del área total tomada para cada retícula. La distribución de los valores promedio de ICVi por cada área urbana analizada, se observan en la tabla 2, lo mismo que la tipificación topográfica de cada área urbana, según características preponderantes:

Tabla 2. Índice de carga visual (ICVI) por cada área urbana y tipificación de cada área.

\begin{tabular}{cll}
\hline Área urbana & ICVi & \multicolumn{1}{c}{ Tipificación } \\
\hline a1 & 26.2 & Estrato alto zona verde \\
a2 & 37 & Comercial de servicios para automotores \\
a3 & 25.7 & Estrato medio, alta densidad de tráfico \\
a4 & 13 & Estrato alto con alta densidad de tráfico \\
a5 & 27.6 & Estrato medio baja densidad de tráfico \\
a6 & 30.7 & Zona de alta afluencia comercial y tráfico \\
a7 & 24.8 & Zona industrial \\
a8 & 37.7 & Estrato bajo con baja densidad de tráfico \\
a9 & 26 & Estrato bajo con alta densidad de tráfico \\
a10 & 22.3 & Estrato alto con baja densidad de tráfico \\
a11 & 26 & Estrato bajo de afluencia comercial \\
a12 & 19.9 & Estrato medio zona verde \\
a13 & 33.7 & Centro geográfico no residencial \\
\hline
\end{tabular}

Para determinar si hubo asociaciones significativas entre los registros de cada nivel de carga visual (nulo, bajo, medio y alto), y los diferentes ítems propiciadores de carga visual considerando los dos campos visuales, en referencia al horóptero visual, también se apeló al estadístico chi-cuadrado, donde la base (N) fue de 1820 registros. Los resultados mostraron una asociación significativa ( $p<.001)$, entre las áreas urbanas y los dos campos visuales cotejados $(1 \mathrm{~N}, 2 \mathrm{~N})$, tal como se muestra en la tabla 3.

Tabla 3. Asociaciones entre los registros de nivel de carga visual y los estímulos (ítems) visuales.

\begin{tabular}{lccr}
\hline \multicolumn{1}{r}{ Ítem con carga } & Nivel de carga & F. relativa F. absoluta \\
\hline PA_1NQ & Nulo & 85,7 & 1560 \\
B_1NQ & Bajo & 57 & 1040 \\
APA_1NQ & Alto & 43 & 780 \\
APA_2NQ & Nulo & 71,4 & 1300 \\
R_1NQ & Bajo & 64,3 & 1170
\end{tabular}




\begin{tabular}{llrr} 
CP_1NQ & Medio & 50 & 910 \\
CP_2NQ & Bajo & 57 & 1040 \\
C_1NQ & Nulo & 85,7 & 1560 \\
V-2NQ & Medio & 50 & 910 \\
CU_1NQ & Nulo & 43 & 780 \\
CU_2NQ & Nulo & 85,7 & 1560 \\
ARH_1NQ & Medio & 35,7 & 650 \\
AT_1NQ & Nulo & 64,3 & 1170 \\
AT_2NQ & Nulo & 71,4 & 1300 \\
& & \\
\hline $\begin{array}{l}\text { Nota: Los códigos de los ítems que implicaron la carga visual, son: PA= Puestos ambulantes; APA= avisos, } \\
\text { pendones y afiches; B= basura; CP= cables y postes; AT= antenas; R= rayones; } V=\text { vallas; ARH= andenes rotos } \\
\text { y huecos; CU=culatas. El código 1NQ, hace referencia al campo visual de primer nivel. El código 2NQ, alude } \\
\text { al campo visual de segundo nivel. }\end{array}$
\end{tabular}

En consideración al análisis estadístico, se observó que para las comparaciones realizadas, se encontraron diferencias significativas $(p<.001)$, con una potencia estadística (1- $\beta$ ) que superó el estándar alto de .80 (Cohen, 1992) y con un tamaño del efecto que estuvo por encima del estándar alto (.50). En referencia a las cargas visuales altas y medias, se encontró que los avisos, pendones y afiches (APA), se asocian con un nivel alto de carga en el campo visual de primer nivel. Los cables y postes (CP), se asocian con una carga visual media también en el campo visual de primer nivel. Las vallas publicitarias (V), están asociadas con un nivel medio de carga visual en el campo visual de segundo nivel. Por último, los andenes rotos y los huecos (ARH), se asocian con una carga visual media dentro del campo visual de primer nivel. Se aprecia que el material publicitario tuvo presencia tanto en los niveles de campo visual $1 \mathrm{~N}$ y $2 \mathrm{~N}$, pero discriminadamente, esto en razón a que las vallas lograron posicionarse en el segundo nivel del campo visual, mientras que los avisos, pendones y afiches, se ubicaron en el campo visual de primer nivel.

Resaltó el hecho de que elementos propios de la infraestructura urbanística, como los andenes y los postes eléctricos, abonaron a la percepción de un nivel medio de carga visual, para los dos ítems dentro del campo visual de primer nivel. Este hecho indica la importancia que tiene la colocación (posicionamiento) de los potenciales estímulos con carga visual, en relación a la totalidad del campo visual y considerando los niveles de contraste existentes, por los cuales los objetos pueden tener mayor o menor nivel de saliencia, pero siempre en relación al ángulo en el cual cada objeto es observado en relación a la línea de horizonte (Kamičaitytè-Virbašienè et al., 2015). Adicionalmente, se destaca que hubo diferencias estadísticamente significativas entre los ICVi de las áreas urbanas analizadas: $\mathrm{F}(12, \mathrm{~N}$ $=1820)=5.113, p<.001$.

En la figura 6 se aprecia que las áreas a2, a8 y a13, destacaron por tener mayor carga visual. Esto puede estar asociado a que las dos son zonas urbanas, en las que hay: talleres de reparación de vehículos, servitecas y puestos de ventas ambulantes. También se aprecia que las áreas a4 y a12, presentaron una media menor en lo que respecta a carga visual percibida, hecho que puede guardar relación con la presencia de zonas verdes dentro del paisaje visual. En ese sentido, la tipología de los escenarios sí puede suponer una diferencia en las cargas visuales percibidas. En efecto, las áreas urbanas que integran áreas verdes con elementos naturales y especies arbó- 
reas que contienen tonalidades verdes, tienen una menor probabilidad de producir el efecto de carga visual percibida (Flad, 1997), a diferencia de zonas que tienen elementos de tipo industrial o construcciones asimétricas que no configuran una homogeneidad visual (Chmielewski et al., 2018; Kamičaitytè-Virbašienè et al., 2015). Las medias obtenidas para los niveles de carga visual de cada área, se grafican y describen en la figura 6.

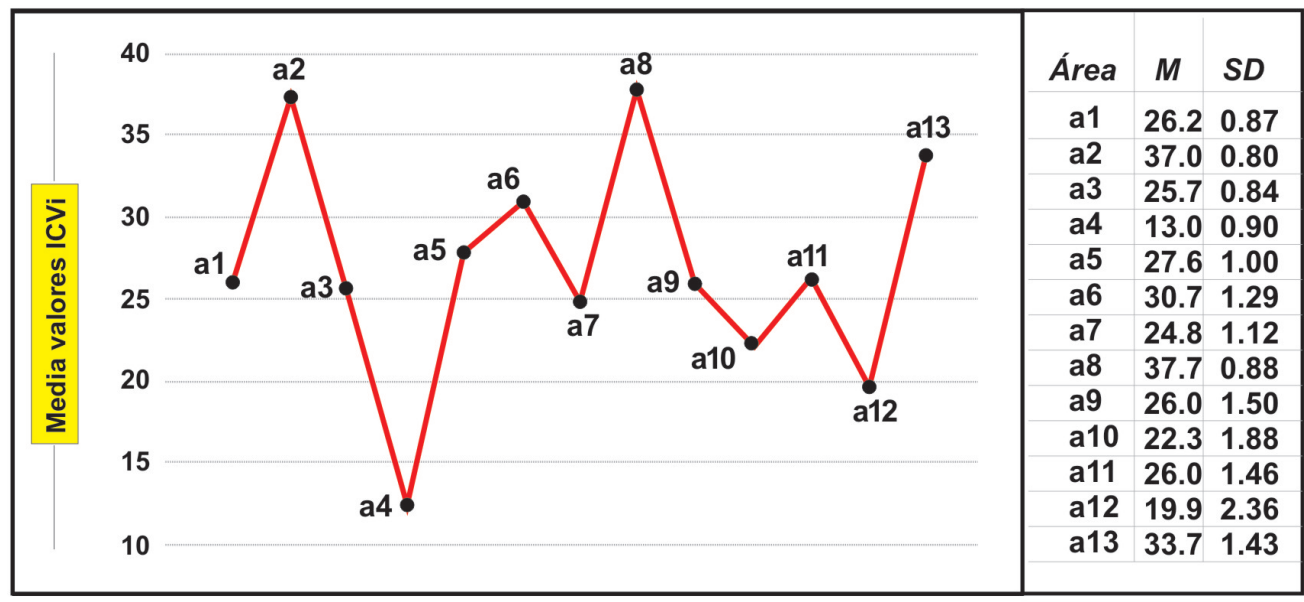

Figura 6. Media de los valores de carga visual ICVi, por cada una de las áreas urbanas analizadas. Los valores medios por cada área con su desviación estándar se aprecian a la derecha.

En el momento de comparar las cargas visuales percibidas de las categorías medio nivel de carga y alto nivel de carga, se encontró una diferencia estadísticamente significativa en favor del nivel alto. Para este propósito, se cotejaron los promedios de las categorías ICVi medio e ICVi alto, donde los resultados estadísticos fueron los siguientes: (ICVi-Medio: $\mathrm{M}=23.63, \mathrm{SD}=4.11$; ICVi-Alto: $\mathrm{M}=34.77, \mathrm{SD}=2.79 ; \mathrm{F}(\mathrm{N}=1820)=21.78$, $p<.001), d=3.17$ (ver figura 7, a la derecha). A su vez, cuando se compararon los campos visuales de primer y segundo nivel (figura 7 a la izquierda), fue percibida más carga visual en el primer nivel, con una diferencia sobre el segundo nivel estadísticamente significativa: $1 \mathrm{~N}: \mathrm{M}=8.18, \mathrm{SD}=$ $12.85 ; 2 \mathrm{~N}: \mathrm{M}=2.42, \mathrm{SD}=5.60) ; \mathrm{U}(\mathrm{N}=260)=5204.5$, $\mathrm{p}<.001), \mathrm{d}=0.58$; tamaño del efecto medio $=.50$. con potencia estadística alta $(1-\beta=.99)$.
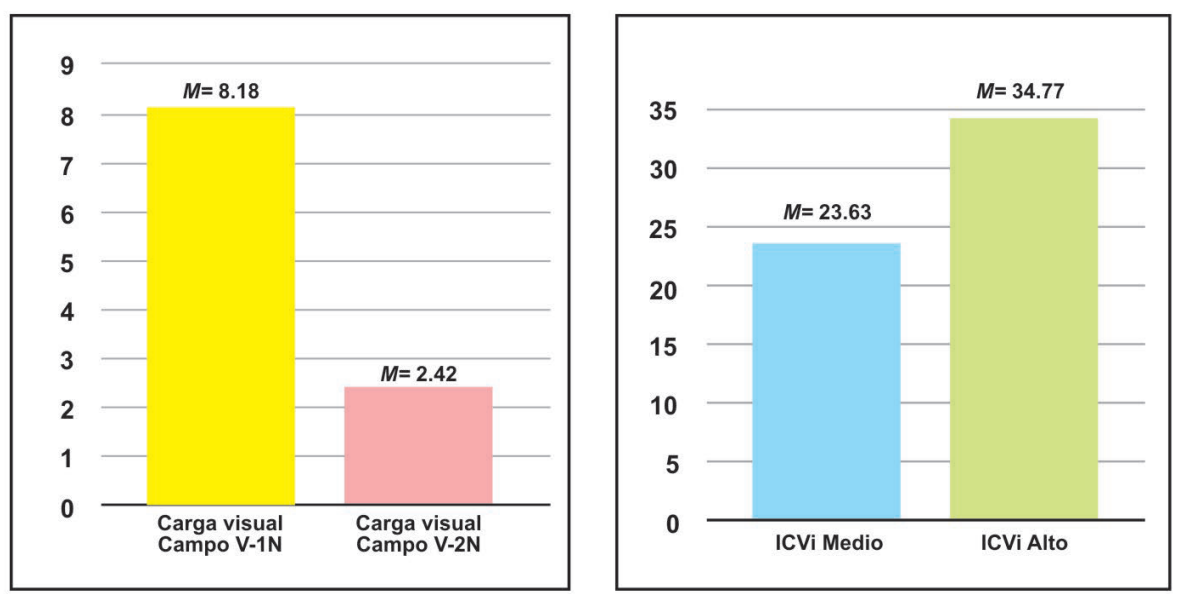

Figura 7. Comparativos de cargas visuales. A la izquierda, las diferencias entre las cargas visuales en los campos visuales de primer y segundo nivel. A la derecha, diferencias entre cargas visuales altas y medias. 
Estos resultados se encuentran en línea con el hecho de que el ojo humano, está mayormente habituado a observar estímulos visuales presentes dentro del área de Panum, en relación a la dirección paralela a la horizontal o trazando vectores por los que sus fijaciones oculares son realizadas hasta los $15^{\circ}$, lo que a su vez implica una relación entre el ángulo dentro del campo visual donde se ubiquen los objetos y la posición del cuerpo humano (Lopez et al., 2009). La estimulación visual que esté en el campo visual de segundo nivel, configurará menor carga visual en comparación a la del primer nivel. Esto permite inferir que las vallas publicitarias que se ubican en lo alto, no propician tanta carga visual como otros objetos dispuestos en ángulos inferiores en relación al horóptero vertical.

\section{Conclusiones}

Dentro de las áreas urbanas de la ciudad de Bogotá que concentran actividad publicitaria, la carga visual percibida es mayor cuando la estimulación visual propiciadora de contaminación visual, se encuentra dentro del campo visual que está por debajo de los $15^{\circ}$. Los objetos que están por encima de este campo visual de primer nivel (como las vallas publicitarias de gran formato), si bien configuran en los observadores carga visual, suponen un índice significativamente menor en relación con las mediciones de carga visual que se reportan en la parte baja del campo visual, en relación al horóptero vertical. La tipología de los paisajes urbanos puede tener una incidencia en la carga visual percibida, donde áreas que contienen elementos naturales pueden tener menor carga con respecto a zonas con material de tipo artificial o industrial.

En estudios precedentes, se ha encontrado que diferentes factores pueden influir en la percepción de carga visual por parte de los observadores, tales como: valores sociales y culturales, estilo de vida e intereses profesionales, experiencias pasadas, género, edad, personalidad y grupos étnicos. En efecto, estudios interculturales han demostrado que las representaciones mentales de los espacios públicos pueden diferir entre personas de diferentes orígenes culturales (Oreg \& Katz-Gerro, 2006, Isaacs, 2000), hecho que reivindica la necesidad de seguir adelantando estudios sobre la problemática de la contaminación visual a nivel mundial.

La investigación acá documentada, evidencia que son diversos los objetos que están efectivamente asociados a la percepción de contaminación visual. Este hecho marca la necesidad de proponer lineamientos concretos que propugnen por disminuir la carga visual percibida, para así abonar en el mejoramiento de la calidad de vida de los ciudadanos.

\section{Agradecimientos}

Los autores agradecen a Christian Schrader y a su equipo "Entorno Urbano: Realidades sobre la comunicación exterior visual". Se agradece a Daniel Arriaga, al equipo directivo de Asomedios, y también a Elizabeth Melo y Javier Melendez, de la ANDA, por sus valiosos aportes y sugerencias.

\section{Referencias}

Alemán, Y. A. (2013). Causas y efectos de la contaminación visual en la arquitectura y la imagen de la ciudad de Arequipa. Editorial 7 Área de Ciencias Sociales, 14, 19.

Aydin, C., \& Nisanci R. (2008). Environmental harmony and evaluation of advertisement billboards with digital photogrammetry technique and GIS capabilities: a case study in the City of Ankara. Sensors 8 (5), 3271-3286.

Bechtel, R. B., Marans, R. W., \& Michelson, W. E. (1987). Methods in environmental and behavioral research. Van Nostrand Reinhold Co.

Chmielewski, S., Lee, D. J., Tompalski, P., Chmielewski, T. J., \& Wężyk, P. (2016). Measuring visual pollution by outdoor advertisements in an urban street using intervisibilty analysis and public surveys. International Journal of Geographical Information Science, 30 (4), 801-818. 
Chmielewski, S., Samulowska, M., Lupa, M., Lee, D., \& Zagajewski, B. (2018). Citizen science and WebGIS for outdoor advertisement visual poIlution assessment. Computers environment and urban systems, 67, 97-109.

Cohen, J. (1992). A power primer. Psychological bulletin, 112 (1), 155.

Cinzano, P., \& Falchi, F. (2014). Quantifying light pollution. Journal of Quantitative Spectroscopy and Radiative Transfer, 139, 13-20.

DANE (s.f.). Línea base de indicadores; estrategias para el fortalecimiento estadístico territorial.

Flad, H. K. (1997). Country clutter: visual pollution and the rural roadscape. The ANNALS of the American Academy of Political and Social Science, 553(1), 117-129.

Frank, S., Fürst, C., Koschke, L., Witt, A., \& Makeschin, F. (2013). Assessment of landscape aesthetics - Validation of a landscape metricsbased assessment by visual estimation of the scenic beauty. Ecological indicators, 32, 222231.

Granda, M. E. (2017). La contaminación visual producida por la publicidad exterior. J. Herrero, \& C. Mateos (Eds), Del verbo al bit 1354-1369. La Laguna, Tenerife: Sociedad Latina de Comunicación Social.

Ha, L., \& Litman, B. R. (1997). Does advertising clutter have diminishing and negative returns?. Journal of Advertising, 26 (1), 31- 42.

Holmqvist, K., Nyström, M., Andersson, R., Dewhurst, R., Jarodzka, H., \& van de Weijer, J. (2011). Eye Tracking. A comprehensive guide to methods and measures. Oxford: Oxford University Press.

Isaacs, R. (2000). The Urban Picturesque: An Aesthetic Experience of Urban Pedestrian Places. Journal of Urban Design, 5 (2), 145-180.

Iveson, K. (2012). Branded cities: outdoor advertising, urban governance, and the outdoor media landscape. Antipode, 44 (1), 151-174.
Kamičaitytė-Virbašienè, J., Godienè, G., \& Kavoliūnas, G. (2015). Methodology of visual pollution assessment for natural landscapes. Journal of Sustainable Architecture and Civil Engineering, 13 (4), 83-91.

Lakshminarayanan, V., Rajaram, V., Joseph, S., \& Beatty, J. A. (2002). Empirical Longitudinal Horopter With Induced Optical Displacment. Investigative Ophthalmology \& Visual Science, 43 (13), 4715-4715.

Lavie, N., Beck, D. M., \& Konstantinou, N. (2014). Blinded by the load: attention, awareness and the role of perceptual load. Philosophical Transactions of the Royal Society B: Biological Sciences, 369 (1641), 1-10.

Lopez, C., Bachofner, C., Mercier, M., \& Blanke, O. (2009). Gravity and observer's body orientation influence the visual perception of human body postures. Journal of vision, 9 (5), 1-14.

Lipshits, M., Mclntyre, J., Zaoui, M., Gurfinkel, V., \& Berthoz, A. (2001). Does gravity play an essential role in the asymmetrical visual perception of vertical and horizontal line length?. Acta Astronautica, 49, 123-130.

López, F. J. (2012). La contaminación visual o perceptiva en el patrimonio histórico. Una breve aproximación para el caso de Osuna. Cuadernos de los amigos de los museos de Osuna, (14), 98-102.

Macdonald, J. S., \& Lavie, N. (2011). Visual perceptual load induces inattentional deafness. Attention, Perception, \& Psychophysics, 73 (6), 1780-1789.

Milam, D., El-Nasr, M. S., Moura, D., \& Bartram, L. (2011). Effect of camera and object motion on visual load in $3 d$ games. In J.C. Anacleto, S. Fels, N. Graham, B. Kapralos, M. Saif El-Nasr, \& K. Stanley (Eds), Entertainment Computing - ICEC 2011. ICEC 2011. Lecture Notes in Computer Science, 6972 113-123. Springer, Berlin: Heidelberg.

Molloy, K., Griffiths, T. D., Chait, M., \& Lavie, N. (2015). Inattentional deafness: visual load leads to time-specific suppression of auditory evoked responses. Journal of Neuroscience, 35(49), 1604616054. 
Olivares, F. (2009). "Cidade limpa" y la contaminación publicitaria en la ciudad. Zer: Revista de estudios de comunicación, 14 (26), 253-275.

Oreg, S., \& Katz-Gerro, T. (2006). Predicting Proenvironmental Behavior CrossNationally: Values, the Theory of Planned Behavior, and ValueBelief-Norm Theory. Environment and Behavior, 38 (4), 462-483.

Rosa, P. J., Esteves, F. \& Arriaga, P. (2014). Effects of fear-relevant stimuli on attention: integrating gaze data with subliminal exposure. Proceedings of IEEE International Symposium on Medical Measurements and Applications, 1, 1-6.

The perception of depth. (Julio, 2011). Recuperado de: http://retina.umh.es/Webvision/ KallDepth.html 